\title{
Programa Nacional de Habitação Rural e modo de morar no campo: reflexões a partir da casa rural na Zona da Mata mineira
}

\author{
CARVALHO, Aline Werneck Barbosa de ${ }^{1}$ \\ PAULA, Nayara Elisa Silva de ${ }^{2}$ \\ PEREIRA, Dafhini Aline Grego ${ }^{3}$
}

1Departamento de Arquitetura e Urbanismo, Universidade Federal de Viçosa - UFV, Viçosa, MG, Brasil. alinewbc@gmail.com

2Departamento de Arquitetura e Urbanismo, UFV, Viçosa, MG, Brasil. nayaraelisa.paula@gmail.com 32Departamento de Arquitetura e Urbanismo, UFV, Viçosa, MG, Brasil. dafhini.a.grego@gmail.com

\begin{abstract}
Resumo
O Programa Nacional de Habitação Rural (PNHR) constitui a vertente rural do Programa Minha Casa, Minha Vida - MCMV e tem como objetivo reduzir o déficit habitacional rural por meio da reforma ou construção de novas moradias. Apesar da importância desse Programa para a fixação do homem ao campo, neste artigo procura-se chamar a atenção para a necessidade de adequação da tipologia de casa do PNHR ao modo de morar na área rural. A pesquisa fundamentou-se na análise da habitação rural em Minas Gerais, mais especificamente na região da Zona da Mata, bem como na análise da legislação que rege o PNHR, como leis, portarias e decretos. Os resultados apontaram que as especificações técnicas mínimas estabelecidas pelo Ministério das Cidades para o PNHR desconsideram o modo de vida rural e os hábitos dos moradores. Embora haja o cuidado de não estabelecer áreas mínimas para os compartimentos, a fixação da área útil total em $36 \mathrm{~m}^{2}$ e 0 dimensionamento induzido a partir do tamanho e descrição do mobiliário mínimo conduzem à formatação de um programa de necessidades muito semelhante ao da tipologia de casa adotado pela versão urbana do Programa Minha Casa Minha Vida.
\end{abstract}

Palavras-Chave: política habitacional, habitação rural, Programa Minha Casa Minha Vida.

\begin{abstract}
The National Rural Housing Program (PNHR) is the rural part of the "Minha Casa, Minha Vida" Program and aims to reduce rural housing deficit through the renovation or construction of new housing. Despite the importance of this program for fixing the men to the field, this paper aims to draw attention to the need to adapt the typology of the house of PNHR to the way of living in rural areas. The research was based on rural housing analysis in Minas Gerais, more specifically in the Zona da Mata region, as well as in the analysis of the legislation governing the PNHR. The results showed that the minimum technical specifications established by the "Ministério das Cidades" disregard the rural way of life and habits of the residents as well. Although not establishing minimum areas to the rooms, both the definition of a total floor area of $36 \mathrm{~m}^{2}$ and the scale induced from the minimum size of the rooms and furniture leads to formatting a program very similar to the type of house adopted by "Minha Casa, Minha Vida" Program in urban areas.
\end{abstract}

Key-words: housing policy, rural housing, "Minha Casa, Minha Vida" Program. 


\section{Introdução}

$\mathrm{O}$ ato de habitar extrapola o entendimento da mera moradia como invólucro físico, cuja principal função é a de abrigo. A célula habitacional é apenas uma parte do habitat, que deve ser entendido como tudo aquilo que circunscreve a vida do ser humano, aí incluídos os serviços e equipamentos urbanos, os meios de locomoção, as condições de localização, os costumes e hábitos de morar e as representações sociais.

Em definição da FAO - Organização das Nações Unidas para Agricultura e Alimentação, o habitat deve ser entendido como o somatório dos espaços onde o homem realiza suas atividades cotidianas, sejam elas atividades produtivas, de serviços, residenciais ou de bem estar geral (FAO, 1975, apud PERES, 2003, p. 86).

A habitação rural, por sua vez, pode ser definida como o modo de ocupação do solo em vista da exploração agrícola. Nesse sentido, "os estudos do habitat rural abrangem todos os elementos do estabelecimento rural: a casa, as dependências de serviço, além do conjunto dos campos de cultura, pastagens, hortas, jardins, estradas, caminhos, etc." (COSTA, 1995, p. 5).

A casa pode ser considerada o elemento central do habitat rural, pois além de servir de moradia, a habitação rural abrange outras funções além da residencial, com a de armazenagem e, até mesmo, de beneficiamento da produção. Nesse sentido, ela representa a sede de uma exploração rural, sendo portanto um importante elemento de organização do meio rural. Com esta conotação, a casa rural reflete na organização do espaço a estratificação social.

Dada a extensão territorial do Brasil e as peculiaridades geográficas, culturais e econômicas, a habitação rural apresenta enorme variedade de tipos, que os autores classificam em função da atividade econômica dominante - o complexo açucareiro, as fazendas de café, as fazendas de cacau, as casas dos seringais -, ou a partir da localização geográfica - casas rurais amazônicas, sulinas, do pescador nordestino, dos colonos açorianos, etc. (COSTA, 1978, p. 9).

O tema abordado neste trabalho liga-se à casa do pequeno proprietário rural em Minas Gerais, com a finalidade de avaliar a adequação das tipologias que vêm sendo adotadas pelo Programa Nacional de Habitação Rural - PNHR ao modo de morar no campo.

Para tanto, procurou-se inicialmente caracterizar a casa rural mineira, tanto numa perspectiva histórica e sociológica quanto sob o aspecto construtivo. Entretanto, considerandose a extensão territorial do Estado e suas diferenciações regionais, optou-se por adotar como recorte espacial a Zona da Mata Mineira. Em seguida, apresentam-se os objetivos e diretrizes do PNHR, focando nas especificações mínimas previstas para as moradias rurais. Por fim, procura-se estabelecer um contraponto entre o modo de vida característico da população que vive na área rural da Zona da Mata Mineira e o modelo de casa que vem sendo adotado pelo PNHR em municípios da região.

\section{A Casa Rural na Zona da Mata Mineira}

No Brasil, são poucos os estudos que tratam sobre a arquitetura civil doméstica no meio rural. Os estudos sobre o modo de vida no campo e, por conseguinte, os hábitos de morar, são quase sempre tratados no âmbito da Antropologia, Sociologia, Geografia e outras áreas das Ciências Humanas e Sociais Aplicadas.

Nesse âmbito destacam-se os estudos de Algranti (1997), Alvim (1998) e Wissenbach (1998), em relevante coleção sobre a Vida Privada no Brasil, e os livros de Carlos Lemos, Nestor Goulart Reis Filho e Luís Saia sobre a arquitetura da casa brasileira.

A literatura acerca da arquitetura rural prioriza a casa-grande dos grandes complexos dos engenhos de açúcar, as fazendas de cacau do Recôncavo Baiano e as fazendas de gado e de café, na região das Minas Gerais, São Paulo e Goiás, que constituíram as residências da 
aristocracia rural $^{1}$. O habitar rural, do homem simples do campo, não tem ocupado espaço na literatura sobre a arquitetura rural.

A literatura acerca da habitação rural em Minas Gerais é ainda mais escassa e, quase sempre, refere-se à arquitetura das fazendas de gado e de café, dos séculos XVIII e XIX. Mesmo o estudo seminal de Sylvio de Vasconcellos - Vila Rica -, que trata sobre a casa mineira, aborda a moradia urbana e sua evolução. Trata-se, entretanto, de importantíssima referência sobre a arquitetura mineira e sobre as técnicas construtivas utilizadas, seja no campo ou na cidade. Segundo Vasconcellos (1981, p. 28),

\begin{abstract}
[...] enquanto a arquitetura urbana em Minas Gerais foi bastante peculiar, a rural foi mais tipicamente mineira ainda. Enquanto a residência comum do litoral foi a casa de dois pavimentos com varanda de canto, e a de São Paulo foi a casa baixa, de taipa de pilão, com varanda aberta e entalada entre dois cômodos na extremidades, em Minas as casas de fazenda erguem-se sobre esteio de madeira [...] Os sistemas construtivos são genéricos de todo o Brasil, mas nas Minas se particularizam pelo apuro técnico e plástico.
\end{abstract}

Outra importante referência sobre a arquitetura popular rural mineira é o belo ensaio fotográfico do arquiteto Marcelo Carvalho Ferraz Arquitetura Rural na Serra da Mantiqueira, complexo montanhoso que corta os estados de Minas Gerais, São Paulo e Rio de Janeiro. Não apenas as imagens dizem muito do modo de morar típico das Gerais, sobretudo nas porções Sul e Leste do Estado, mas o texto sensível que acompanha as fotografias traduz o modo simples de morar do homem do campo e a relação intrínseca entre a casa e a natureza. Neste livro o autor registra tudo que compreende o "habitat" rural mineiro: a casa isolada ou no vilarejo, a "decoração" no interior das casas, o paiol para guarda de cereais, a pinguela $^{2}$, o galinheiro, o chiqueiro, o curral, os cochos para o gado, o monjolo, o "quarador", as pequenas cobertas para guarda das carroças ou charretes e estocagem da lenha, a horta, o

\footnotetext{
1 Sobre a arquitetura das fazendas mineiras ver: BENINCASA, 2010; LELIS, 1996.

2 Prancha de madeira usada como ponte para atravessar pequenos riachos.

${ }^{3}$ Local de quarar, isto é, clarear a roupa ao sol.
}

pomar e até mesmo as capelas de beira de estrada, local de louvor das famílias, junto com seus agregados e escravos. Alguns traços dessa arquitetura registrada por Ferraz (1992) são muito típicos da Zona da Mata Mineira.

Lelis (1996) realizou um estudo pormenorizado do sistema construtivo de sete fazendas localizadas num raio de $25 \mathrm{~km}$ da cidade de Viçosa, preenchendo uma lacuna existente na bibliografia mineira no que se refere aos processos construtivos adotados na arquitetura rural da região em questão, "considerando que a produção existente trata o assunto de uma forma generalizada, mostrando as características das edificações em todo o estado, que muitas vezes não se enquadram às de Viçosa" (LELIS, 1996, p. 3). Dentro da área escolhida e a partir da documentação existente, procurou-se resgatar as técnicas construtivas e os materiais empregados, reconhecendo a obra do colono "que muitas vezes, arranjando-se como possível, criava soluções que se enraizavam profundamente na cultura brasileira, identificando-se, portanto, com expressiva parcela da produção da arquitetura do país" (LELIS, 1996, p. 3-4).

A habitação dos pequenos produtores rurais da região da Zona da Mata mineira foi estudada na sua essência por Ludwig (1994) em sua dissertação de Mestrado, na qual reconstrói o modo como os produtores e suas famílias têm se envolvido com a questão da habitação, descrevendo a expressão física da habitação, sua percepção do espaço e o significado a ela atribuído. Para tanto, a autora estudou três comunidades rurais do município de Coimbra, localizado a $15 \mathrm{~km}$ de Viçosa. As características da habitação rural dos pequenos produtores, identificadas pela autora, repetem-se com grande regularidade em toda a região.

A casa rural vernácula, propriamente dita, é despojada: construída em pau-a-pique, emboçada e pintada de cores claras, com estrutura portante de madeira; piso de terra batida ou de cimento grosso, elevado do chão para proteger contra a umidade externa; janelas de madeira, de vergas retas, com uma única folha que se abre para o exterior; telhados de 
quatro águas, de telhas cerâmicas do tipo capacanal, sem forro ou com forros de esteira. $O$ fogão a lenha está sempre presente, na maioria das vezes localizado nas varandas dos fundos, local da lida doméstica. Muitas casas também têm o forno de barro, localizados em posição estratégica, fora do corpo da casa, mas ao lado da cozinha. O mobiliário reduz-se ao mínimo necessário, é simples e até tosco, e a decoração diz tudo sobre o modo de viver da família: as panelas caprichosamente areadas, assim como os demais utensílios da cozinha, são expostos com orgulho, para mostrar 0 cuidado da dona de casa; os quadros dos santos de devoção, do Sagrado Coração de Maria e do Sagrado Coração de Jesus ilustram a religiosidade do mineiro que mora na roça, assim como as cruzes cobertas de tiras de plástico, papel de seda ou papel crepon. A singeleza é o traço maior desta arquitetura. (Figura 1).

Figura 1: Habitação no meio rural na Zona da Mata Mineira: a) frente da casa; b) paiol e coberta para charrete ou carroça; c) extensão de coberta nos fundos do paiol; d) cruz revestida com tiras de plástico ou de papel.
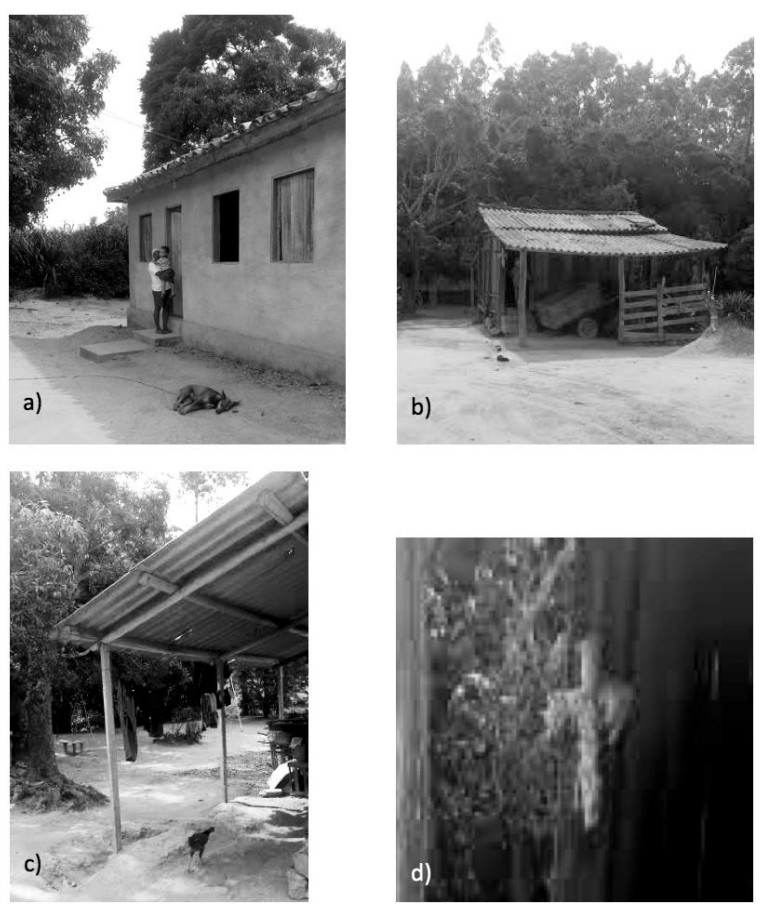

Fonte: Autores

As imagens da habitação rural representadas na Figura 1 são um exemplo típico da tipologia de casa rural encontrada na zona rural do município de Viçosa, localizado na Zona da Mata Mineira. Não se encontra na casa rural a subdivisão tripartite em área social, privativa e de serviço. A casa possui planta nuclear, com a sala ocupando posição central, para a qual se abrem as portas dos dois quartos e a cozinha. Como a sala não é um local de permanência, sua dimensão é quase sempre reduzida, embora esse uso venha se alterando a partir da introdução da televisão. Os quartos destinam-se especificamente ao descanso noturno e por essa razão possuem pequenas dimensões. Normalmente as casas têm dois ou três quartos: o do casal e dos filhos. O banheiro abre-se para a cozinha e constitui, em geral, um ambiente pouco valorizado no conjunto da moradia. A cozinha é, por excelência, o local de permanência dos moradores e o "centro interacional" na casa dos pequenos produtores. É na cozinha que são feitas as refeições do dia a dia, embora a varanda localizada nos fundos também possa ser utilizada para esta destinação. Ela é o ambiente que conserva mais características dos costumes tradicionais do meio rural, principalmente pela presença do fogão a lenha. Embora atualmente se encontre o fogão a gás, o fogão a lenha permanece, seja pela preservação dos costumes, seja pelo alto custo do gás. Aos fundos da casa, comunicando-se diretamente com a cozinha, existe uma varanda coberta, que se constitui como um ambiente predominantemente de serviço. Normalmente, a varanda apresenta um tanque de lavar roupas ou uma bacia, entre outros objetos, como gaiolas, feixes de lenha e vasos de plantas (LUDWIG, 1994).

A casa eleva-se alguns degraus em relação ao solo, para evitar a umidade. A cobertura é feita em telhado de quatro águas, de telha cerâmica do tipo capa-canal, com estrutura de madeira e sem forro. As janelas e portas são de madeira, com uma única folha que se abre para dentro.

As construções secundárias diferenciam-se da casa quanto ao acabamento e aos materiais utilizados. Enquanto a casa, feita de pau-apique ou alvenaria, é pintada de caiação branca 
ou de barro branco ("barreada"4), o paiol, a coberta para a charrete ou carroça, o curral ou outras pequenas construções são feitas com réguas de madeira ou de bambu, cobertas com telhados de duas águas, de telhas tipo canal, de amianto ou até mesmo de sapé (LUDWIG, 1994).

A área fronteiriça à casa é formada pelo terreiro, cuidadosamente mantido varrido, apesar de ser de terra. $\mathrm{O}$ jardim é parte integrante do terreiro e da entrada da casa, formado por canteiros de flores singelas, como margaridas, roseiras, hibiscos e outros. As aves (galinhas, galos, patos, marrecos, gansos, perus) e outros animais (gatos, cachorros e porcos) ficam soltos e o galinheiro, quando existe, é um cercado de bambu. As hortas estão sempre presentes, cercadas por bambu, e assim como as árvores frutíferas, localizam-se nos fundos da casa.

Ludwig (2006) destaca que a vida rural é marcada pela regularidade das práticas regidas pelos ciclos da natureza e pelas tradições que os perpassam, e se apoia na relação dos moradores com a terra e nas relações sociais que dela se originam. Este cotidiano está intrinsecamente ligado ao espaço do habitar (a casa e seus espaços secundários) que, como enfatiza a autora, transforma-se em "lugar", fortemente dotado de identidade.

\section{O Habitar no Meio Rural Contemporâneo}

A dispersão das casas rurais no território existe ainda hoje graças à estrutura fundiária brasileira, fundada no latifúndio. Nas grandes cidades, a expansão da mancha urbana reduziu ou até mesmo eliminou a área rural, entretanto, em grande parte do território brasileiro, nos municípios com pequenos núcleos urbanos e grandes áreas rurais, ainda persiste o tipo de ocupação rarefeita, próprio do espaço rural herdado das nossas raízes coloniais.

A nova racionalidade que adentra o campo, como consequência do processo de

\footnotetext{
${ }^{4}$ Coloca-se o barro num balde e junta-se água. Formase uma espécie de "mingal" branco, com o qual se pintam as casas.
}

urbanização e de modernização das atividades agrárias, a partir da Segunda Guerra Mundial e mais recentemente, a partir do processo de globalização e de introdução das novas tecnologias de informação e comunicação (TICs), tem se expressado no modo de viver na área rural. No momento em que a fronteira entre o urbano e o rural praticamente desaparece e os diferentes universos culturais se interpenetram, as diferenças entre os modos de vida no campo e na cidade assumem contornos também pouco delimitados, repercutindo na habitação rural de várias formas ${ }^{5}$.

Nas casas reformadas mais recentemente, encontram-se outros materiais de acabamento, como pisos de cerâmica, janelas de vidro basculantes com esquadrias de alumínio ou chapa de aço, azulejos na cozinha e no banheiro e laje maciça ou forro de PVC, conforme aponta pesquisa realizada por Guimarães, Pinto e Fiúza (2013), em que se buscou compreender as influências do processo de urbanização do campo nas condições de moradia das famílias rurais do município de Araponga, MG, também localizado na Zona da Mata Mineira. Tal trabalho aponta que há indícios de interferência dos indicadores de urbanização nas moradias, tanto em relação ao acesso a serviços de infraestrutura (como melhoria dos serviços de água encanada e energia elétrica), como nos aspectos ligados ao interior da casa, entretanto também se registra a permanência de características e formas de morar tradicionais, como a permanência de objetos associados a adornos, como flores, imagens de santos, objetos confeccionados artesanalmente e retratos de família.

\section{A Casa Rural no PNHR}

O PNHR - vertente rural do PMCMV - tem como objetivo "subsidiar a produção ou reforma de imóveis aos agricultores familiares e

\footnotetext{
${ }^{5}$ Sobre o rural contemporâneo, ver: ABRAMOVAY, R. Funções e medidas da ruralidade no desenvolvimento contemporâneo. Rio de Janeiro: IPEA, 2000 (Texto para discussão, n. 702); MONTE-MÓR, R. O que é o urbano no mundo contemporâneo. Revista Paranaense de Desenvolvimento, Curitiba, n.111, p.09-18, jul./dez. 2006, entre outros.
} 
trabalhadores rurais (...)" (Art. 11, Lei n. 12.124/2011), nas propriedades rurais, posses e agrovilas, em terrenos que não ultrapassem quatro módulos fiscais ${ }^{6}$.

O público alvo do PNHR é a população que vive no campo, como agricultores familiares, trabalhadores rurais, assentados do Programa Nacional de Reforma Agrária - PNRA, pescadores artesanais, extrativistas, silvícolas, aquicultores, maricultores, piscicultores, ribeirinhos, povos indígenas, comunidades quilombolas e demais comunidades tradicionais. Os beneficiários são divididos em três grupos de renda, sendo o grupo 1 correspondente à menor faixa, abrangendo famílias com renda bruta anual até $R \$ 15.000,00$, atendidas com subsídio integral (recursos do Orçamento Gerald da União).

De acordo com as Especificações Mínimas do PNHR, a casa rural deve conter: sala, 2 dormitórios (um para o casal e outra para duas pessoas), cozinha, área de serviço coberta (externa), circulação e banheiro.

Estas especificações não estabelecem área mínima de cômodos, exceto a largura mínima da cozinha $(1,80 \mathrm{~m})$, banheiro $(1,50 \mathrm{~m})$ e sala $(2,40 \mathrm{~m})$. Esta determinação visa dar liberdade aos projetistas para dimensionar os ambientes de acordo com o mobiliário previsto, evitando conflitos com legislações estaduais ou municipais que versam sobre dimensões mínimas dos ambientes. Portanto, para o dimensionamento dos cômodos, as especificações do PNHR definem a quantidade e as dimensões do mobiliário mínimo.

A casa deve ter área mínima de $36,0 \mathrm{~m}^{2}$, excluindo a área de serviço, mas os projetos deverão prever solução de ampliação. Trata-se de área muito reduzida, mesmo para o caso de apenas dois quartos.

O pé direito mínimo deve ser de 2,30m nos

\footnotetext{
${ }^{6}$ O limitador de até 4 módulos fiscais, por família, para acesso ao PNHR, não se aplica às terras indígenas e quilombolas cuja posse é coletiva e a definição dos limites das terras é respaldado por estudos antropológicos de institutos voltados para o reconhecimento e a proteção e dessas comunidades.
}

banheiros e 2,50m nos demais cômodos, tal como foi estabelecido para a casa urbana do PMCMV. Deve-se observar, também, que se trata de um pé direito bastante baixo, o que denota preocupação com a economia de materiais e mão de obra.

A sala de estar deve conter, além do sofá, uma mesa com 4 cadeiras, configurando-se, portanto, como sala de estar conjugada com sala de refeições. A cozinha por sua vez, restringe-se ao espaço de cocção e preparo dos alimentos, contendo uma pia sobre bancada de $1,20 \mathrm{~m} \times 0,50 \mathrm{~m}$, fogão a gás, geladeira $\mathrm{e}$ armário sob a bancada. $O$ espaço para refeições foi deslocado para a sala, ao contrário do que é comum no meio rural, onde as refeições normalmente são feitas na cozinha ou na varanda dos fundos. A cozinha mineira, sobretudo no meio rural, é sempre o local onde a família gosta de se reunir, para "prosear", perto do fogão a lenha.

A área de serviço prevista no PNHR tem conotação tipicamente urbana. Nela incorporase uma modernidade: a máquina de lavar roupas, além do tanque. Inclusive a própria denominação - "área de serviço" - não é própria do meio rural, onde as tarefas de lavar e passar roupas ocorrem na "varanda" aos fundos da casa.

No banheiro teve-se o cuidado de exigir a previsão de área para pessoas em cadeiras de rodas fazerem a transferência ao vaso sanitário e ao box, o que indica preocupação com a acessibilidade por pessoas com deficiência ou com mobilidade reduzida. Assim, apesar de se estabelecer uma largura mínima de 1,50m, o banheiro tenderá a não ter área muito reduzida. O cuidado com a acessibilidade está presente em outros cômodos da casa, na medida em que se exige espaço livre de obstáculos em frente às portas de no mínimo $1,20 \mathrm{~m}$, bem como a possibilidade de se inscrever, em todos os cômodos, o módulo de manobra para cadeiras de rodas sem deslocamento para rotação de $180^{\circ}(1,20 \mathrm{~m} \times 1,50 \mathrm{~m})$, definido pela NBR9050/04. Deve-se observar, entretanto, que se este módulo for inserido em todos os cômodos, a área útil da casa será muito 
superior a $36 \mathrm{~m}^{2}$.

O dormitório de solteiro deve ser dimensionado para duas pessoas e conter como mobiliário mínimo: 2 camas, um criado-mudo e um guarda-roupas pequeno $(1,50 \mathrm{~m} \times 0,50 \mathrm{~m}) . \mathrm{O}$ mesmo mobiliário é previsto para o dormitório de casal, adotando-se, logicamente, a cama de casal.

Nas Figuras 2 a 4 ilustram-se três modelos de plantas baixas de moradias do PNHR adotados na região da Zona da Mata Mineira, localizados nos municípios de São Miguel do Anta, Viçosa e Guiricema, respectivamente.

Figura 2: Planta baixa da casa do PNHR no município de São Miguel do Anta - MG, sem escala.

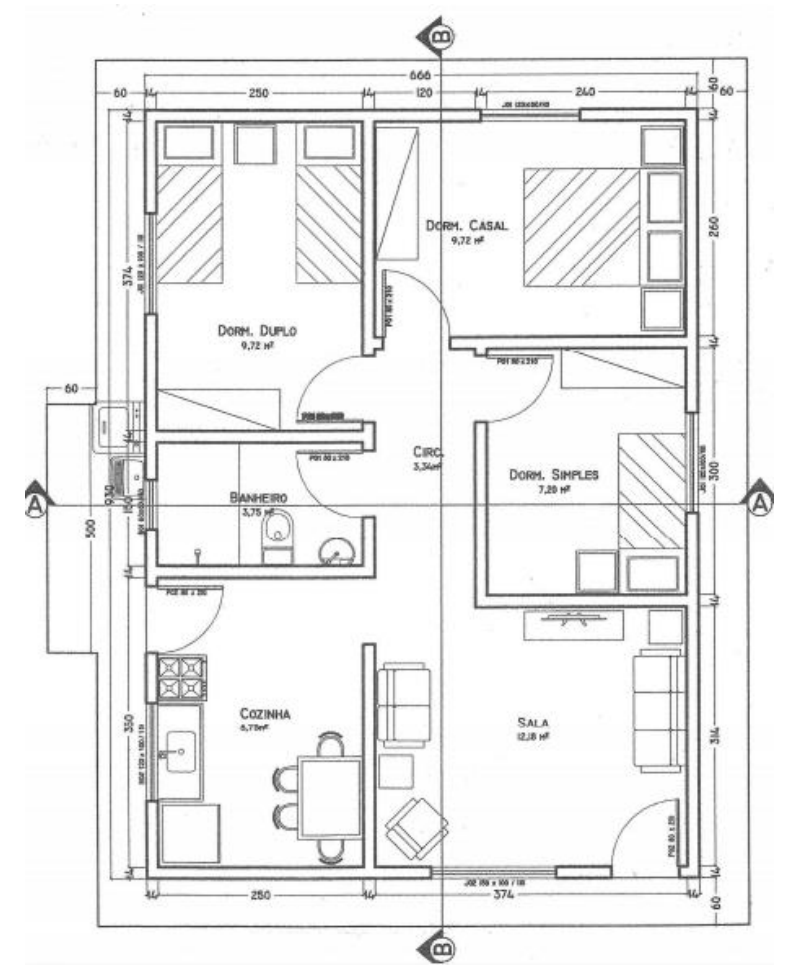

Fonte: SANTOS (2014), p. 40.
Figura 3: Planta baixa da casa do PNHR a ser construída no município de Viçosa - MG, sem escala.

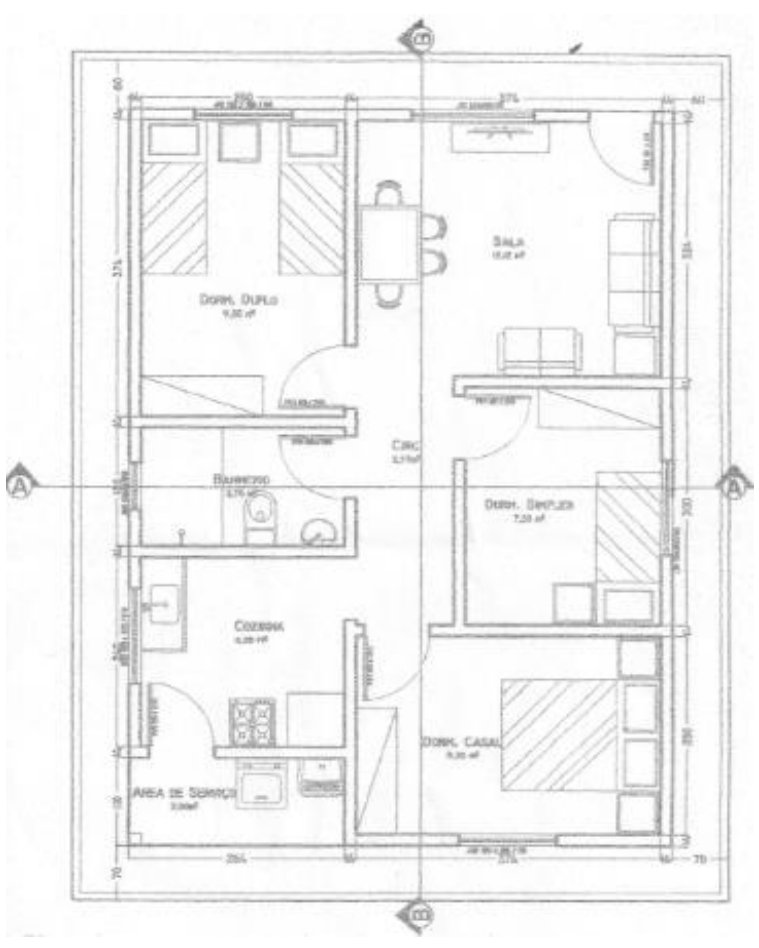

Fonte: Fornecida por representante da Entidade Organizadora.

Figura 4: Planta baixa da casa do PNHR no município de Guiricema - MG, sem escala.

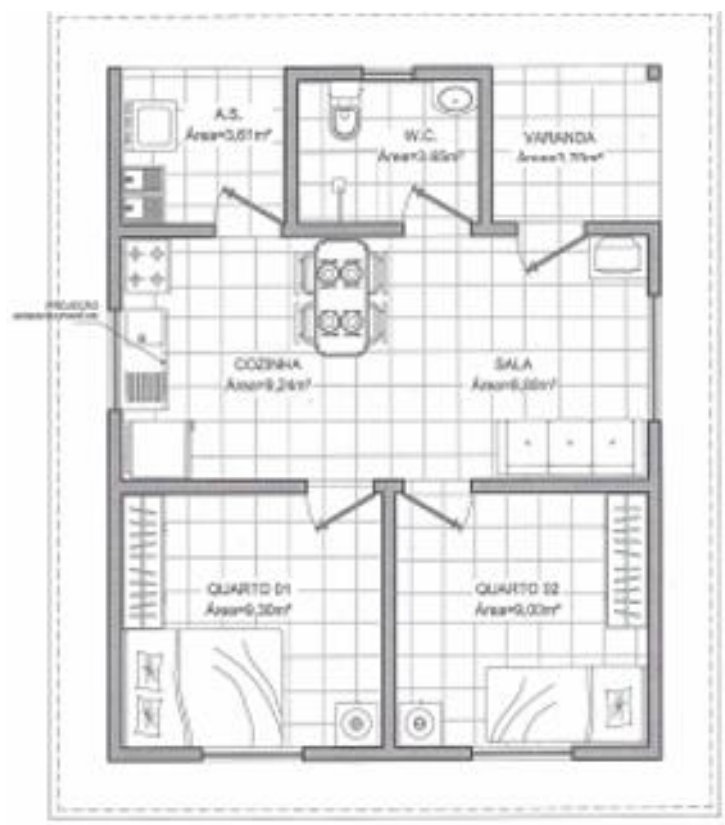

Fonte: SANTOS (2014), p. 39.

O programa de necessidades das unidades habitacionais dos municípios de São Miguel do Anta e Viçosa compõe-se de sala, 3 quartos, cozinha, banheiro e espaço para o tanque e a máquina de lavar roupa. As tipologias de casa adotadas nestes municípios reproduzem o 
modelo de casa urbana adotado pelo PMCMV, à exceção do número de quartos. Em São Miguel do Anta, embora o espaço de refeições tenha sido inserido na cozinha, a varanda dos fundos está ausente. Em Viçosa, o espaço de refeições está incluído na sala e as dimensões da cozinha e da área de serviço são muito reduzidas.

No caso de Guiricema, observa-se uma tentativa de aproximação da tipologia própria da moradia rural, com a sala ocupando posição central, embora seja conjugada com o espaço da cozinha, o que não é típico das casas rurais. A varanda é incluída no programa de necessidades, mas não se conforma da mesma maneira que ocorre na região, onde a varanda é o espaço de serviço, situada aos fundos da casa.

Em nenhuma delas foi inserido o fogão a lenha. Mesmo assim, todas as plantas possuem área superior a $36 \mathrm{~m}^{2}$, conforme pode ser observado na Tabela 1.

Tabela 1: área das unidades habitacionais do PNHR nos municípios de São Miguel do Anta, Viçosa e Guiricema, na Zona da Mata de Minas Gerais.

\begin{tabular}{lll}
\hline Município & $\begin{array}{l}\text { Área útil } \\
\left(\mathbf{m}^{\mathbf{2}}\right)\end{array}$ & $\begin{array}{l}\text { Área total } \\
\left(\mathbf{m}^{2}\right)\end{array}$ \\
\hline São Miguel do Anta & 54,29 & 61,94 \\
Viçosa & 54,44 & 61,94 \\
Guiricema & 47,39 & 53,71 \\
\hline
\end{tabular}

\section{Análise do Projeto}

Quanto aos sistemas construtivos, as especificações mínimas do PNHR indicam que a casa deve ter cobertura em telha cerâmica, sobre estrutura de madeira ou metálica, com beirais de no mínimo $60 \mathrm{~cm}$. Nas Regiões Centro-Oeste, Sul e Sudeste admite-se telha em fibrocimento, com espessura mínima de $6 \mathrm{~mm}$, sobre estrutura de madeira ou metálica, porém será obrigatório o uso de forro, em madeira ou PVC, ou laje de concreto.

O revestimento interno deve ser feito em pintura sobre reboco ou gesso, enquanto o revestimento externo deve ser texturizado ou adotar-se pintura acrílica sobre reboco. Nas áreas molhadas - banheiro, cozinha e área de serviço - deve-se adotar azulejo com altura mínima de 1,50 m em todas as paredes. Prevêse a adoção de pisos cerâmicos em toda a área interna da unidade habitacional.

As portas e janelas podem ser de madeira ou metálicas; estipula-se uma área de 1,20 $\mathrm{m}^{2}$ para as janelas dos quartos e $1,50 \mathrm{~m}^{2}$ para as da sala, sendo admissível uma variação de até $5 \%$.

Sob o aspecto das instalações elétricas e hidrossanitárias deve-se:

- prever vários pontos de tomadas elétricas (2 na sala, 4 na cozinha, 1 na área de serviço, 2 em cada dormitório, 1 no banheiro, 1 ao lado do tanque e mais 1 tomada para chuveiro elétrico), 1 ponto de antena de TV na sala e um ponto de iluminação em cada ambiente;

- prever circuitos independentes para chuveiro, tomadas e iluminação;

- prever reservatório de água de capacidade mínima de 500 litros;

- prever solução para máquina de lavar roupas (ponto elétrico, hidráulico e de esgoto).

A instalação de aquecimento solar para aquecimento da água do chuveiro e a construção de cisterna pluvial são opcionais. Sobressaem alguns cuidados, como a necessidade de proteção da alvenaria externa por meio de calçada em concreto, com largura mínima de 0,50m ao redor da edificação e de no mínimo $1,20 \mathrm{~m}$ em frente ao tanque e à porta da cozinha. Também se exige a adoção de sistema de impermeabilização da fundação, porém não se recomenda que a casa fique elevada em relação ao solo, como é típico das construções rurais, solução sabiamente adotada para proteger os pisos e paredes da umidade.

Quanto à infraestrutura externa, exige-se que as vias de acesso estejam em condições de tráfego de veículos e que o sistema de abastecimento de água seja adequado às condições locais. Entretanto, não se apresentam soluções próprias do meio rural. Quanto ao esgotamento sanitário, admite-se o uso de fossa séptica e sumidouro. No caso da energia elétrica, deve-se utilizar a solução 
adotada para a região, ou fazer protocolo de pedido à Concessionária de Energia, firmado pela Entidade Organizadora ou pelo beneficiário.

Por fim, recomenda-se que "os projetos arquitetônicos deverão apresentar compatibilidade com as características regionais, locais, climáticas e culturais da localidade/comunidade, mediante compensação na melhoria da unidade habitacional e comunicação à Secretaria Nacional de Habitação-SNH do MCidades", o que dá ao gestor e ao profissional responsável pela elaboração do projeto arquitetônico e pela construção das unidades habitacionais a liberdade de ampliar a área da moradia, adaptando 0 seu arranjo funcional às necessidades e características regionais e das famílias beneficiadas.

\section{Conclusões}

Ao comparar o modo de viver $e$ as características da casa rural na Zona da Mata de Minas Gerais com as especificações mínimas do Ministério das Cidades e os exemplos de moradia do PNHR adotados na região, pode-se concluir que não tem havido um maior cuidado com a consideração das características regionais e culturais próprias das localidades rurais.

Por desconsideração ou desconhecimento do modo de vida rural, tem-se repetido o mesmo modelo de moradia adotado pelo PMCMV nas áreas urbanas. As próprias especificações técnicas mínimas estabelecidas pelo Ministério das Cidades para o PNHR concorrem para este procedimento. Embora haja o cuidado de não fixar áreas mínimas para os compartimentos, o dimensionamento induzido a partir do tamanho e descrição do mobiliário mínimo conduzem à formatação de um programa de necessidades muito semelhante ao da casa urbana, como: cozinha muito pequena, sem espaço para fogão a lenha e para refeições, o que não é típico das áreas rurais; mesa de refeições integrada à sala, o que também não é típico da casa rural vernacular, cujas refeições são feitas na cozinha ou na varanda dos fundos, e área de serviço restrita ao espaço do tanque e máquina de lavar.

A varanda pode ser incorporada ao corpo da casa (ultrapassando a área mínima), porém, quase sempre é incluída na sua parte frontal, como acontece nas casas da cidade, cujas varandas se voltam para a rua, ao contrário do que ocorre no campo, onde as varandas são destinadas às atividades de serviço.

Há aspectos que, por um lado, são desejados pelos moradores, seja por remeter simbolicamente ao modo de vida urbano, seja pela facilidade de limpeza e manutenção, como a utilização de materiais de acabamento que não são próprios das casas rurais: pisos cerâmicos (porcelanato), esquadrias de alumínio, estrutura do telhado feita em perfis de aço e forro de PVC. A incorporação deste vocabulário formal é assimilada pelos construtores, pois também facilita a construção.

Entretanto, apesar da nova racionalidade que adentra o campo, expressa nos materiais e no acesso a bens e serviços produzidos na cidade, é fundamental que a casa a ser construída pelo PNHR preserve as relações funcionais $e$ simbólicas que expressam o modo de vida rural.

\section{Referências}

ALGRANTI, L. M. Famílias e vida doméstica. In: SOUZA, L. M. (Org.). História da vida privada no Brasil: cotidiano e vida privada na América Portuguesa. São Paulo: Companhia das Letras, 1997. p. 83-155.

ALVIM, Z. Imigrantes: a vida privada dos pobres no campo. In: SEVCENKO, N. História da vida privada no Brasil - República: da Belle époque à era do rádio. São Paulo: Companhia das Letras, 1998. p. 215-287.

BENINCASA, V. Velhas fazendas: arquitetura e cotidiano nos Campos de Araraquara, 18301930. São Carlos, SP: EDUFSCAR, 2003.

COSTA, I. B. Tipos de habitação rural no Brasil. Rio de Janeiro: SUPREN, 1978.

COSTA, C. E. S. Habitação rural: uma proposta de racionalização pela autoconstrução. Rio de 
Janeiro: EDUR, 1995.

FERRAZ, M. C. Arquitetura rural na Serra da Mantiqueira. São Paulo: Quadrante, 1992.

GUIMARÃES, E. P.; PINTO, N. M. A.; FIÚZA, A. L. C. Os reflexos da urbanização do campo nos modos de moradia das famílias residentes na zona rural do município de Araponga - MG. Oikos: Revista Brasileira de Economia Doméstica, Viçosa, v. 24, n.2, p. 163-184, 2013.

LELIS, R. F. Arquitetura rural na região de Viçosa (MG). Processos Construtivos. 1996. 158 f. Dissertação (Mestrado em Arquitetura e Urbanismo) - Universidade Federal da Bahia, Salvador, 1996.

LEMOS, C. A. C. História da casa brasileira. São Paulo: Contexto, 1989.

LUDWIG, M. P. Morar no que é dos outros, morar no que é da gente: uma análise da habitação de pequenos produtores rurais. 1994, 165 f. Dissertação (Mestrado em Extensão Rural) - Universidade Federal de Viçosa, Viçosa, 1994.

Tempos de espaços da vida cotidiana da comunidade rural de Casa Nova, Zona da Mata de Minas Gerais. Oikos: Revista Brasileira de Economia Doméstica, Viçosa, v. 17, n.3, p. 87-104, 2006.

PERES, Renata Bovo. Habitação rural. Discussão e diretrizes para políticas públicas, planejamentos e programas habitacionais. 2003, 2012 f. Disssertação (Mestrado em Arquitetura e Urbanismo) - Universidade de São Paulo, São Carlos, 2003.

REIS FILHO, N. G. Quadro da arquitetura no Brasil. São Paulo: Perspectiva, 2004.

SAIA, Luís. Morada paulista. São Paulo: Perspectiva, 2012.

SANTOS, S. N. Realidade, significado e expectativas do Programa Nacional de Habitação Rural: o caso de Guiricema e São Miguel do Anta. 2014. 137 f. Dissertação (Mestrado em Economia Doméstica) Universidade Federal de Viçosa, Viçosa-MG,
2014.

VASCONCELLOS, S. Vila Rica. São Paulo: Perspectiva, 1977.

VASCONCELLOS, S. Mineiridade. Ensaio de caracterização. São Paulo: Abril Cultural S. A. e Industrial, 1981.

WISSENBACH, M. C. C. Da escravidão à liberdade: dimensões de uma privacidade possível. In: SEVCENKO, N. História da vida privada no Brasil - República: da Belle époque à era do rádio. São Paulo: Companhia das Letras, 1998. p. 49-130. 